\section{INCONTINENCE IN OLD PEOPLE}

By John C. Brocklehurst, M.D. Pp. xiii + rgr, with 62 illustrations. Edinburgh: E. \& S. Livingstone. I95I. 30s.

This monograph is based on a most comprehensive study of 412 senile patients incontinent of urine or faeces or both, found in the general and mental wards of five Glasgow hospitals. Aged incontinents present a sociological and clinical problem, the magnitude of which is better appreciated when it is realized that II per cent. of patients in general wards are found to suffer from this distressing and disabling condition, and that 26 per cent. of these cases occupy a bed for periods from six months to two years.

The book is divided into three parts :-

Part I reviews the literature on the subject and discusses at length the anatomical and physiological considerations of micturition and defaecation with perhaps slight lack of accuracy in describing the nerve supply to the urethral sphincter.

Part 2 discusses the aetiology of incontinence in old people. Three important chapters are devoted to cystometric and rectometric study in a large number of cases, and many graphic illustrations are presented. Three precipitating factors are (a) cerebro-vascular accidents, (b) becoming bedfast, and (c) increasing mental confusion. It is surprising to note that enlargement of the prostate plays only a minor part in this condition.

Part 3 presents the management of incontinence in old people. In this section present methods of treatment are discussed and new ways are presented in which management of these difficult cases may be facilitated.

The volume is, indeed, well worth studying by all engaged in the care of the aged sick.

\section{THE PHARMACOLOGY AND THERAPEUTICS OF THE MATERIA MEDICA}

By Walter J. Dilling, M.B., Ch.B., M.P.S. I gth Edition. Pp. xxxii +598 . London : Cassell \& Co. 195I. $21 \mathrm{~s}$.

In the review of the roth edition of this valuable book published in our August number, it was stated that "its appearance has been delayed until after the death of its well-known author, Professor Walter J. Dilling.' The extensive revisions which have kept it abreast of modern developments were, in fact, completed by the author himself.

\section{BRONCHIAL ASTHMA}

By R. J. Whiteman, M.B., Ch.M., F.R.A.C.S. Pp. $x i+r 84$. London: H. K. Lewis. I95I. I 5 s.

The author of this little book is an Australian surgeon specializing in otorhinolaryngology, and his experience, extending over some 30 years of clinical practice, has made him an enthusiastic advocate of the theory that nasal discharge is due to infection, that it is the main cause of asthma, chronic bronchitis and baso-motor rhinitis. $\mathrm{He}$ believes that the treatment he has evolved will cure chronic nasal catarrh and by so doing will abolish or materially ameliorate the clinical conditions caused by it.

He states that the absorption of chronic nasal discharge, either directly from the nose or from the stomach when swallowed, causes a toxaemia which produces a clinical syndrome with the following features:-Headache, nasal obstruction, sneezing and anosmia, digestive symptoms such as flatulence, anorexia and 'bilious attacks,' cough and dyspnoea,' dizziness, lassitude and emotional instability. The appearance of the patient with a pasty skin and dark rings under the eyes he believes to be characteristic of the syndrome.

His treatment of nasal discharge consists of the following regime:-(a) admission to hospital where a double intranasal antrostomy is performed, followed by daily lavage with normal saline, (b) frequent and prolonged inhalations of a weak vapour containing menthol and eucalyptus either from a thermos of hot water or with a face mask, (c) the patient is discharged from hospital after a fortnight but continues the inhalations for some hours daily for a further fortnight, (d) on the slightest symptom of a fresh cold, he must go to bed immediately in a room with an even temperature and start inhalations again, continuing treatment until all symptoms have disappeared.

He stresses the importance of educating the patient to recognize the earliest manifestation of a fresh cold, such as slight stuffiness of the nose, increase in the amount of discharge or even a headache or 'bilious attack.' The patient or relative must report the onset of colds and progress of his symptoms to the physician at frequent intervals during the first six months of treatment. In children the author believes that antrostomy is unnecessary except in special cases.

The author points out that this regime is tedious and time consuming and that the average asthmatic may spend up to three months in bed during the first six months of treatment. As a rule after six to nine months the asthma disappears and fresh ' colds' become infrequent. In the majority of his patients, after a year the patient has lost all symptoms and has gained a great deal of weight. He has such faith in his treatment that he believes if patients do not get well it is because they have not been carrying out the treatment properly.

In Chapter $\mathrm{V}$ he gives the results of an investigation of his treatment in a series of severe asthmatics under the auspices of the Department of Health, Sydney. Of 43 patients followed up for two to three years, 29 (67 per cent.) were very much improved, 8 (I9 per cent.) much improved and none failed to improve in some degree. Of 35 patients observed between one and two years, 33 (94 per cent.) were much improved and 2 (6 per cent.) improved. The case histories quoted show that after successful treatment the patients have apparently lost their sensitivity to allergens which previously produced attacks of asthma or rhinitis.

One is always sceptical of a treatment which 